\title{
GNAS-Related Loss-of-Function Disorders and the Role of Imprinting
}

\author{
Agnès Linglart $^{a, b}$ Stéphanie Maupetit-Méhouas ${ }^{c} \quad$ Caroline Silve $^{a, b}$ \\ ${ }^{a}$ Endocrinology and Diabetology for Children and French Center of Reference for Rare Disorders of

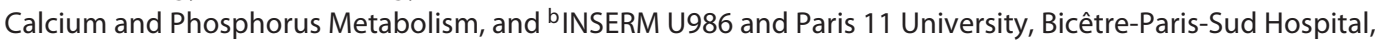 \\ Le Kremlin Bicêtre, and 'INSERM U1103, CNRS 6293, Clermont Université, Clermont-Ferrand, France
}

\section{Key Words}

Parathyroid hormone - Imprinting .

Pseudohypoparathyroidism · GNAS

\begin{abstract}
GNAS (guanine nucleotide-binding protein, a stimulating) is a complex imprinted locus coding, besides the a-stimulatory subunit of the $G$ protein, the paternally (extra-large, antisense and $A / B$ ) and maternally (neuroendocrine secretory protein) transcripts. Heterozygous mutations in the coding sequence of GNAS produce dominant phenotypes (combination of resistances to hormones signaling through G-protein-coupled receptors, osteodystrophy and obesity) that depend on the parental origin of the mutated allele. Likewise, alterations in the methylation at promoters of GNAS transcripts, associated or not with deletions of imprinting control regions in the nearby STX16 gene or within GNAS, prompt resistance to parathormone when affecting the maternal allele. Therefore, imprinting of GNAS is the determining factor for the variability of the phenotype. Knowledge of the various phenotypes is necessary for genetic counseling as well as an appropriate therapeutic balance between regular follow-up, prevention of disease complications and iatrogeny.

Copyright $\odot 2013$ S. Karger AG, Basel
\end{abstract}

\section{Introduction}

The story of GNAS (guanine nucleotide-binding protein, a stimulating; MIM No. 610540) and parathormone (PTH) resistance began in 1942 when Fuller Albright [1] first described the absence of calcemic or phosphaturic response to parathyroid extracts in patients with 'hypoparathyroidism' and osteodystrophy. In the late $60 \mathrm{~s}$, immunometric PTH assays confirmed the association of clinically evident hypoparathyroidism and elevated circulating levels of PTH in patients with similar phenotypes [2]. Functional, then genetic, defects in Gsa, the a-stimulatory subunit of the $G$ protein, have been identified in 1990 as the cause of the historical syndrome of Albright hereditary osteodystrophy (AHO) and PTH resistance, also termed 'pseudohypoparathyroidism (PHP) type 1a' (PHP1a) [3]. In 2000, the discovery of epigenetic changes at the GNAS locus controlling Gsa expression solved the mystery of isolated PTH resistance described as PHP type $1 \mathrm{~b}$ (PHP1b) [4].

All the PHP type 1 subtypes (absence of cAMP and phosphaturic response to exogenous PTH infusion), although they overlap, have now been linked to a genetic or epigenetic defect in GNAS, whereas the cause of the PHP type 2 is still a matter of debate. Initially, PHP type 2 was

\section{KARGER}

E-Mail karger@karger.com

www.karger.com/hrp
(C) 2013 S. Karger AG, Basel

$1663-2818 / 13 / 0793-0119 \$ 38.00 / 0$
Agnès Linglart, $\mathrm{MD}, \mathrm{PhD}$

Department of Pediatric Endocrinology and Diabetology and INSERM U986 Bicêtre Paris-Sud Hospital, 78 avenue du Général Leclerc

FR-94270 Le Kremlin Bicêtre (France)

E-Mail agnes.linglart@bct.aphp.fr 


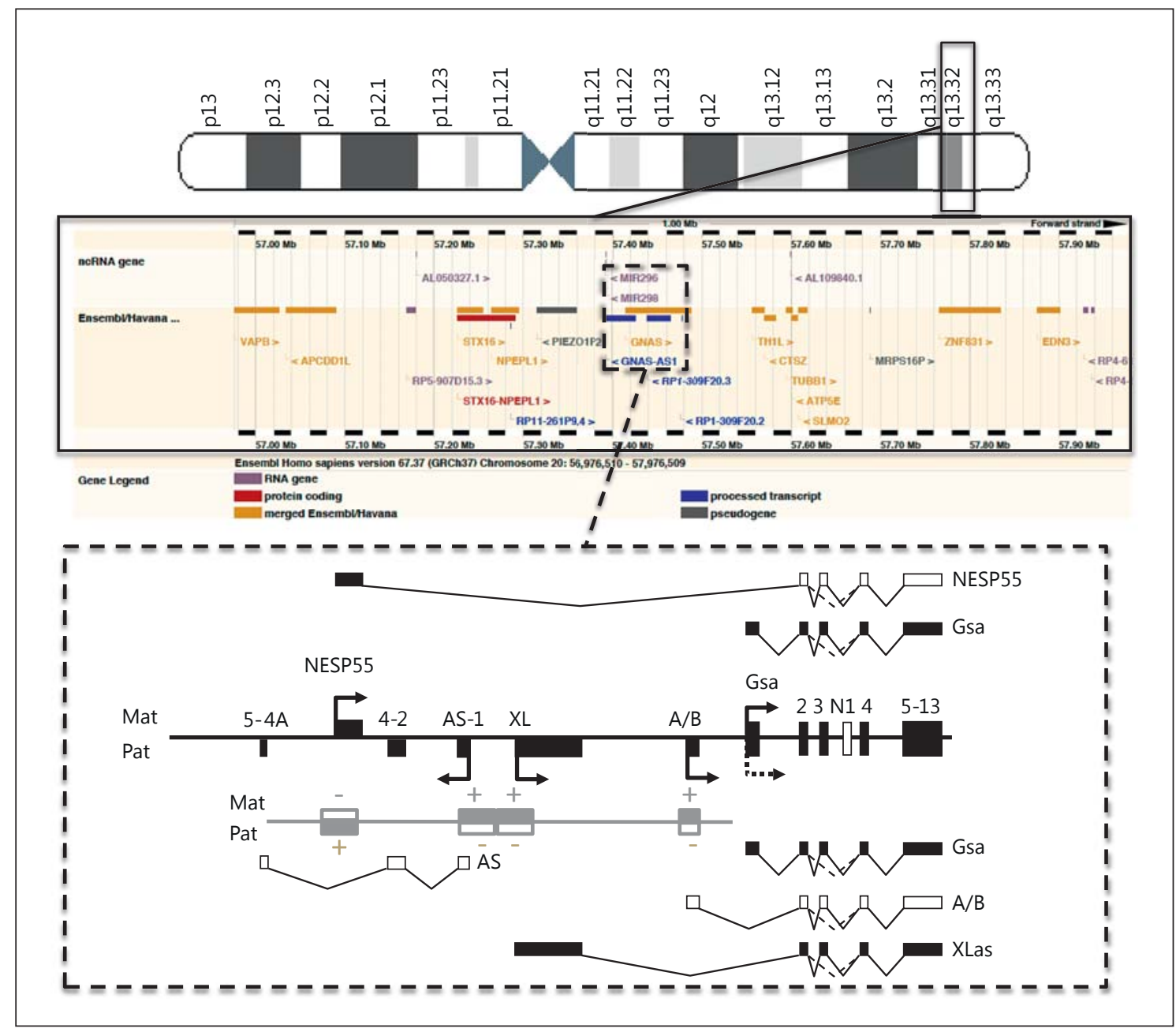

Fig. 1. The imprinted human GNAS locus, on chromosome 20 (upper panel), close to the STX16 gene (middle panel; http://www.ensembl.org/Homo_sapiens/Location/View?r=20:57466719-57486300;time=1343400097) and coding maternal (NESP), paternal (AB, AS and XL) and biallelic (Gsa) transcripts. Black boxes = Coding exons; white boxes = non-coding exons; grey boxes $(+)=$ methylated promoters; empty grey boxes $(-)=$ unmethylated promoters; arrows = transcription (direction and parental origin).

defined as an adequate rise in nephrogenic cAMP, albeit without phosphaturic response to exogenous PTH infusion, in the absence of AHO, and attributed to a defect in cAMP effectors [5]. This definition is challenged today by our and other groups' recent discovery that mutations in the regulatory subunit of the protein kinase A (gene PRKA$R 1 A$ ) cause acrodysostosis, an extreme form of AHO with urinary cAMP response to exogenous PTH in the presence of hormone resistance, including PTH and thyroid-stimulating hormone (TSH) resistance [6-8]. Altogether, the former definition of PHP appears obsolete and should be progressively replaced by a classification of GNAS-related disorders with references to the mechanism of the diseases.

\section{GNAS Imprinting}

Gsa is one $\alpha$-subunit of the heterotrimeric $G$ proteins required for the signaling of the seven transmembrane domain receptors. Gsa is encoded by the imprinted GNAS locus. Imprinting refers to mechanisms that lead to the repression of gene expression from one parental allele. Genes subjected to parental imprinting contain imprinting control regions in differentially methylated regions (DMRs). In most loci, the parent-specific expressed transcripts are associated with a pattern of non- or low-methylated DNA, whereas the non-expressed transcripts are associated with a pattern of methylated DNA [9]. 
Table 1. PTH resistance and GNAS-related diseases

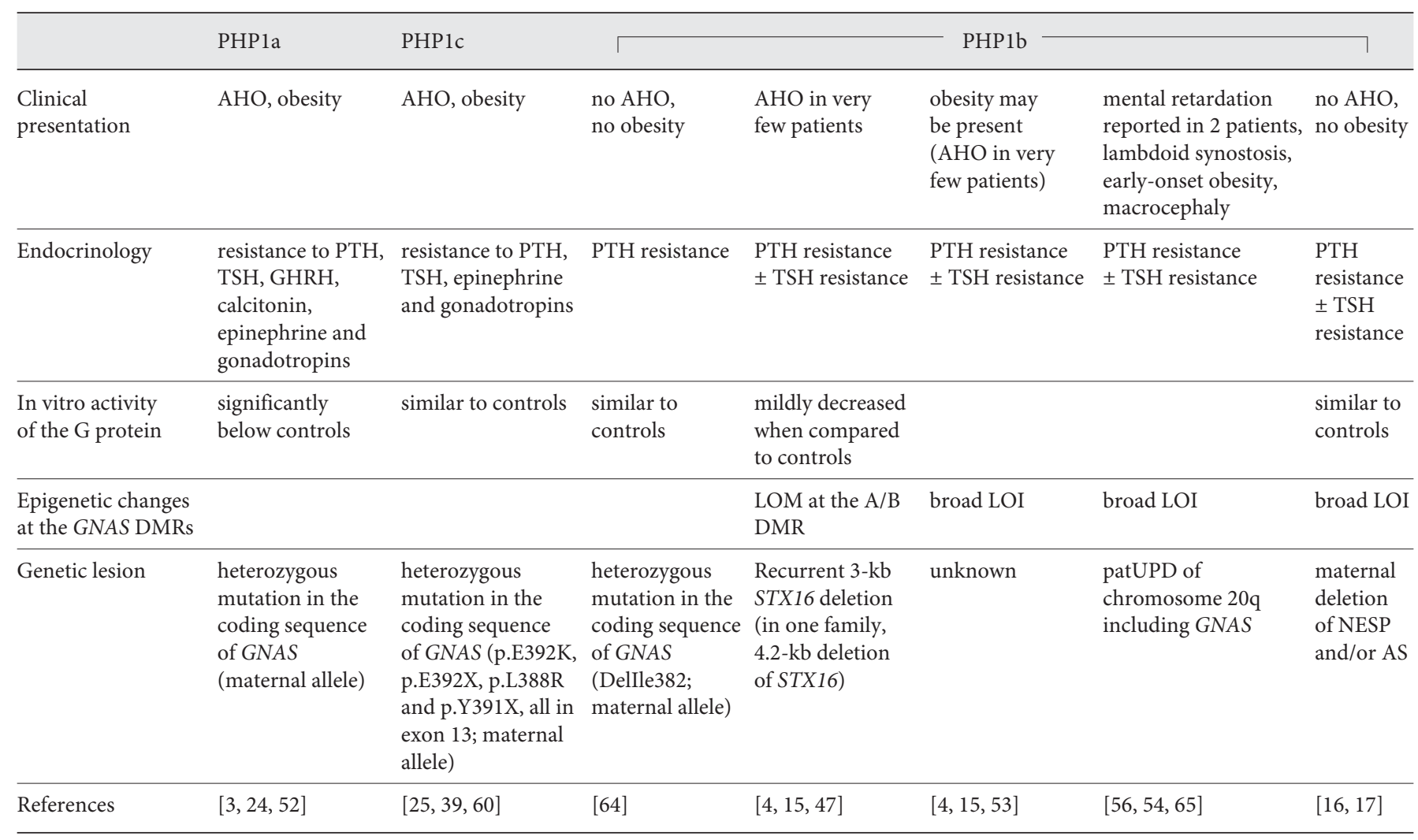

We describe here the different phenotypes, genetic and epigenetic defects that have been reported to illustrate the heterogeneity of the diseases and the need for a new classification. GHRH = Growth hormone-releasing hormone; LOM = loss of methylation; LOI = loss of imprinting; patUPD = paternal uniparental disomy.

The imprinted human GNAS locus produces several transcripts comprising Gsa: A/B (also named 1A), extra-large (XL), the antisense transcript (AS) and the transcript coding neuroendocrine secretory protein 55 (NESP) [10]. Due to differential methylation of their promoters, most transcripts of this locus originate from one parental allele only. XL, A/B and AS are transcribed from the paternal allele; NESP is transcribed from the maternal allele only [11]. The promoter of Gsa is not differentially methylated, and therefore, Gsa expression arises from both alleles in most tissues (fig. 1). However, Gsa expression is restricted to the maternal allele in several tissues including the renal proximal tubule, the thyroid, the pituitary and the gonads [12-14]. In humans, two imprinting control regions of GNAS have been identified within or close to the GNAS locus. One is located within the STX16 gene and controls the establishment of imprinting at the A/B DMR only [15]; the other, encompassing AS exons 3 and 4, controls the establishment of imprinting over the entire GNAS locus [16-18].

\section{Disorders Related to GNAS Genetic and Epigenetic Defects}

\section{PHP1a (OMIM No. 103580)}

PHP1a is a rare autosomal dominant disease due to a defect in the expression or function of Gsa (table 1). Clinical features depend on the mono- or biallelic transcription of Gsa in tissues. In addition to resistance to hormones that signal through G-protein-coupled receptors (GPCRs), patients affected with PHPla present with a collection of features including $\mathrm{AHO}$ and obesity. In our experience, PHP1a is diagnosed early (at about 6.5 years) during the investigation of a symptomatic hy- 


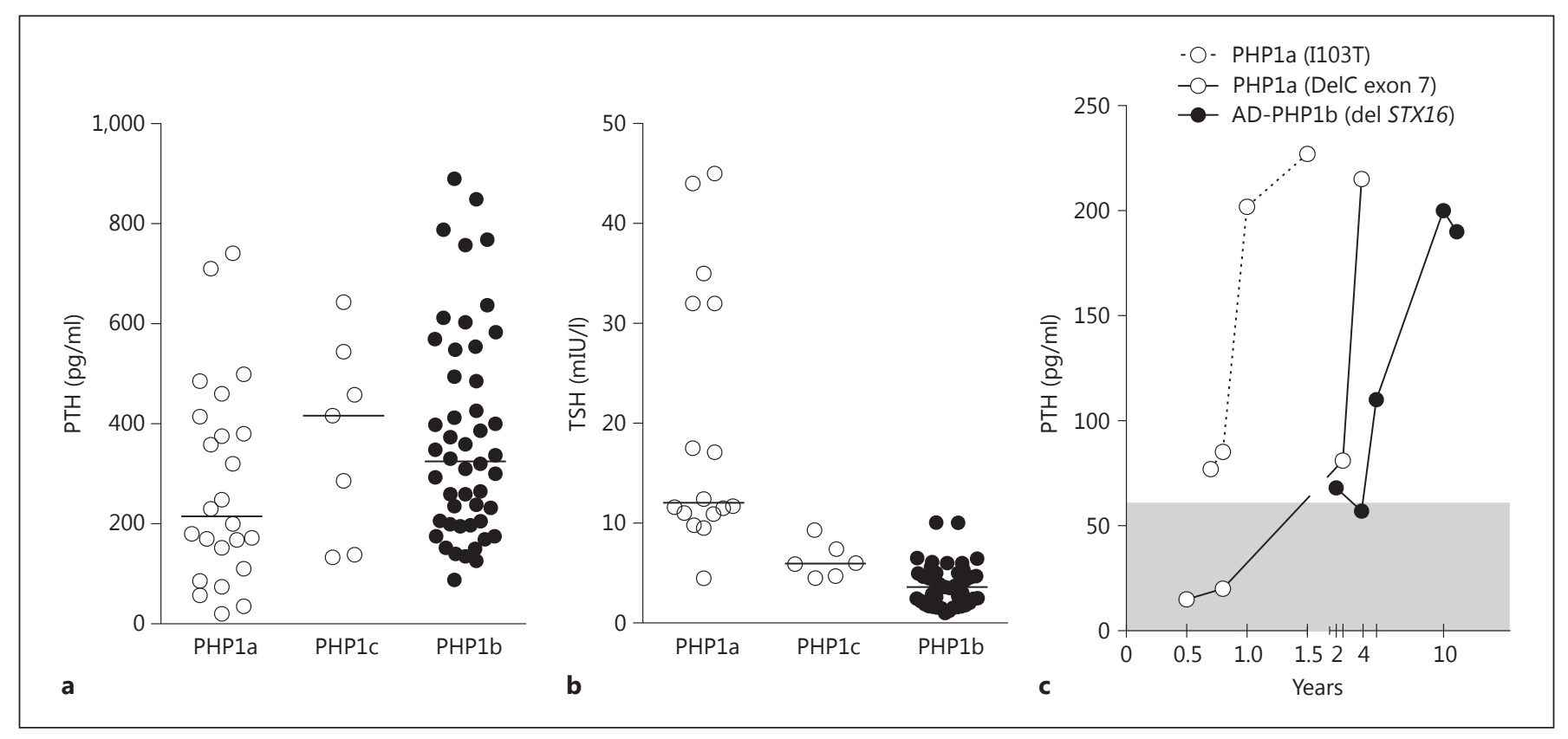

Fig. 2. a, b PTH and TSH resistance in PHP1a, PHP1c and PHP1b. Note that (1) all patients carry a genetic or epigenetic defect at the GNAS locus, (2) 3 patients affected with PHP1a were diagnosed through neonatal screening (values of TSH >30 mIU/l), and (3) data for PHP1c were extracted from Linglart et al. [25] and Thiele et al. [39]. c Evolution of PTH in 2 patients affected with PHP1a and 1 patient affected with autosomal dominant PHP1b and carrying a maternal STX16 deletion.

pocalcemia, heterotopic ossifications, growth retardation, familial screening, hypothyroidism or developmental delay.

\section{Resistance to Hormones Binding to GPCRs}

Resistance to PTH manifests as the association of low serum calcium, elevated serum phosphate and elevated circulating PTH in the absence of 25-OH-vitamin D deficiency and renal insufficiency (fig. 2). Absent at birth, PTH resistance gradually develops during the first months or years of life [19]. Phosphate and PTH levels increase first, followed by a decrease in calcemia. In the renal proximal tubule, the defect in PTH signaling likely tapers the 1a-hydroxylation of 25-OH-vitamin $\mathrm{D}$, hence the $1,25-(\mathrm{OH})_{2}$-vitamin D production, and increases the tubular phosphate reabsorption. In the distal tubule, calcium reabsorption also depends on the PTH-driven cAMP production. However, most likely due to the biallelic expression of Gsa in the distal tubule, urinary calcium reabsorption is close to normal in patients with PHP1a (personal data) and may be involved in the long-term tolerance of PTH resistance. The disease is often revealed during events requiring increasing amounts of calcium such as vitamin D deficiency or pubertal growth spurt.
Resistance to TSH is found in most, if not all, patients and contributes to the diagnosis of PHP1a. It is characterized by an elevated TSH $-19.7 \pm 3.3 \mathrm{mIU} / \mathrm{l}($ mean $\pm \mathrm{SE})$ in our series and $4.9 \mathrm{mIU} / \mathrm{l}$ in the study of Balavoine et al. [20] - a low-normal free T4 with no goiter. Usually present at birth, TSH resistance may be revealed through neonatal screening programs. Patients affected with PHPla also display resistance to TRH and calcitonin without symptoms [20, 21]. Cryptorchidism, often bilateral, is frequent in boys. A defect in INSL3 signaling, the hormone responsible for testicular descent, could be incriminated as its receptor couples to Gsa [22]. Girls present with delayed menarche (mean $14.0 \pm 1.9$ years, approximately 1.2 years later than counterparts) [23] and elevated follicle-stimulating hormone levels (150-200\% of the upper normal range), yet normal luteinizing hormone levels [24, 25].

\section{Albright Hereditary Osteodystrophy}

Most patients affected with PHP1a present with bone dysplasia including brachymetacarpy (mainly 4 th and 5 th metacarpals), brachydactyly (fig. 3) and/or brachymetatarsy (present in all patients with variable degrees), narrowed lumbar shaft and undersized femoral necks. Absent at birth, bone dysplasia develops over time, especially 


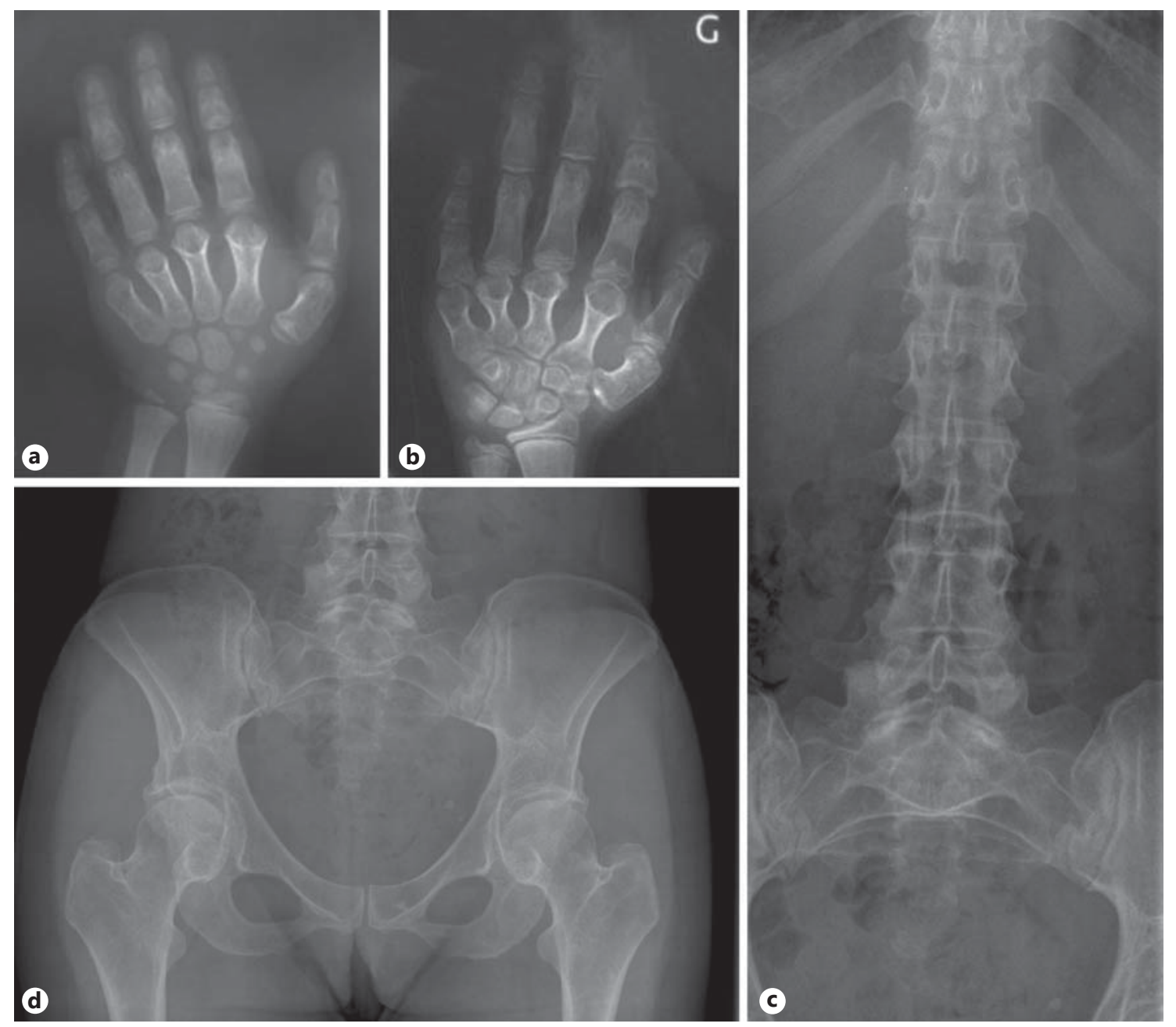

Fig. 3. Brachymetacarpy in a 6- (a) and 12-year-old (b) young girl with PHP1a and a W154X mutation of GNAS. Note the fused epiphyses at the age of 12 . Narrowed lumbar shaft (c) and short femoral necks (d) in a 27-year-old woman with PHP1a and a 4-bp deletion in exon 7 of GNAS.

during puberty, and most likely results from the deficient PTH-related peptide signaling during endochondral bone formation. In fact, loss of function mutations of PTHLH (the gene encoding PTH-related peptide) are associated with similar bone shape abnormalities [26]. The bone density of the patients is roughly normal, yet patients seem prone to rheumatologic complications such as slipped femoral epiphysis or osteoarthritis [27, 28].

Adult short stature is common in patients: $-2.5 \pm 0.3$ and $-3.0 \pm 0.9$ (mean $\pm \mathrm{SD}$ ) height $\mathrm{z}$-score in Long et al. [29] and our series, respectively. Most children with PHP1a have normal stature until they undergo rapid and premature closure of the epiphyses between 10 and 15 years of age (fig. 3). Short stature results from both defi- cient endochondral bone formation and growth hormone-releasing hormone resistance found in about $70 \%$ of the patients [30].

Heterotopic ossifications (osteoma cutis) are a specific feature of Gsa haploinsufficiency. Usually superficial (in the derma or subcutaneous fat), made of mature bone with central bone marrow elements, they may progress unforeseeably superficially or within deeper tissues [31].

Developmental delay and cognitive dysfunction have been reported repeatedly in textbooks, including the study by Fuller Albright [1] in 1942. About $70 \%$ of the patients affected with PHP1a exhibit a moderate to severe cognitive impairment (meaning that $30 \%$ do not have any impairment) [32]. 


\section{Obesity}

Obesity is a major feature of the disease, although patients are unevenly affected (mean body mass index $1.8 \pm$ 0.3 ) [29]. Three contributing factors have been identified: resistance to epinephrine (a lipolysis-stimulating hormone acting through Gsa) [33], the potent anti-adipogenesis effect of Gsa established in vitro [34], and the loss of stimulation of energy expenditure by central melanocortins [35]. An additional layer of complexity arose through the discovery of the opposite effects of the GNAS transcripts on glucose metabolism and obesity [36].

\section{Diagnostic Struggle}

Obesity, AHO and mental retardation have been described in patients with $2 \mathrm{q} 37$ deletions and/or HDAC4 haploinsufficiency [37]. Brachydactyly and hormonal resistance are seen in patients with acrodysostosis and PRKAR1A mutations [6]. Hyperphosphatemia, AHO and TSH resistance allow the differential diagnosis with hyperparathyroidism due to vitamin $\mathrm{D}$ deficiency. To document the absence of urinary cAMP production and the increase in urinary phosphate excretion and to distinguish PHP type 1 from type 2, examination of the renal response to the infusion of exogenous PTH (former Ellsworth-Howard test replaced by the infusion of recombinant $\left.\mathrm{PTH}_{1-34}\right)[6,38]$ may be required. The erythrocyte bioassay to assess Gsa activity contributes to demonstrate the impact of novel mutations or to establish phenotypegenotype correlations [39].

\section{Molecular Diagnosis of PHPIa}

The diagnosis of PHP1a relies on the identification of a heterozygous loss-of-function mutation of the maternal coding sequence of GNAS (exons 1-13). All types of mutations can be found, such as deletions, insertions, amino acid substitutions or stop codons. Three hot spots are located in exons 6, 7 and 13; mutations may also lie in the alternatively spliced exon 3 [40]. The maternal origin of the mutated allele may be identified through parental transmission or haplotype studies [25]. Methylation changes at regulatory regions of GNAS have been found in a few patients with PTH resistance and mild features of AHO, exposing the overlap between the disease variants [41-43].

\section{PHPType 1c}

Factually, PHP type 1c (PHP1c) describes patients with PTH resistance (fig. 2), AHO and normal Gsa in vitro activity. Thiele and colleagues $[25,39]$ have identified muta- tions in the C-terminal region of Gsa (p.R391X, p.E392K, p.E392X, p.L388R) in a subset of patients affected with PHP1c. These mutations prevent the coupling of Gsa to receptors, yet preserve cAMP generation through the activation of the adenylyl cyclase. Most in vitro assays of Gsa activity solely examine the ability of Gsa to activate the adenylyl cyclase, which explains the results found in PHP1c.

\section{Pseudo PHP or Isolated AHO}

Patients affected with pseudo PHP (pPHP) have first been identified within relatives of patients affected with PHP1a. They present with AHO, no hormone resistances and harbor the exact same mutation of Gsa than their siblings albeit on the paternal allele. Recent observations have shown that patients affected with pPHP are not obese [29] and do not have cognitive impairment [32]. Nonetheless, they are short and may have heterotopic ossifications, sometimes more severe than their PHP1a counterparts [44].

\section{Progressive Osseous Heteroplasia (OMIM No. 166350)}

Progressive osseous heteroplasia $(\mathrm{POH})$ is a rare disorder of osteogenesis, developing during infancy, characterized by heterotopic bone in the derma and subcutaneous fat. Bone plaques eventually fuse and progress deeper into fascia, skeletal muscles, tendons and ligaments, leading to ankylosis and preventing natural limb growth. Inflammation may trigger or worsen the expansion of heterotopic bone. Kaplan and colleagues [45] noted features of AHO and subsequently identified GNAS as the diseasecausing gene. Mutations in the coding sequence of Gsa found in patients with $\mathrm{POH}$ are also found in patients with PHP1a or pPHP, although they are exclusively located on the paternal allele, and principally, severely affect protein function. $\mathrm{POH}$ has been associated with intrauterine growth retardation, although some of the reported patients may be considered as PPHP rather than $\mathrm{POH}$ [44]. Altogether, we and others propose that pPHP and $\mathrm{POH}$ are both extremes of a common disease.

\section{PHP1b (OMIM No. 603233)}

PHP $1 \mathrm{~b}$ is a rare disease due to defective Gsa signaling in selected tissues including the renal proximal tubule and the thyroid. Because of abnormal methylation at the 
Fig. 4. Bone features of PHP1b. a, b Bone lesions resembling rickets with irregular and widened metaphysis in a 12-year-old boy with PHP1b and the recurrent $3-\mathrm{kb}$ deletion in STX16. X-rays were performed at diagnosis because of bone pain. Transparent metaphyseal stripes (c) and increased bone matrix transparency $(\mathbf{d}, \mathbf{e})$.
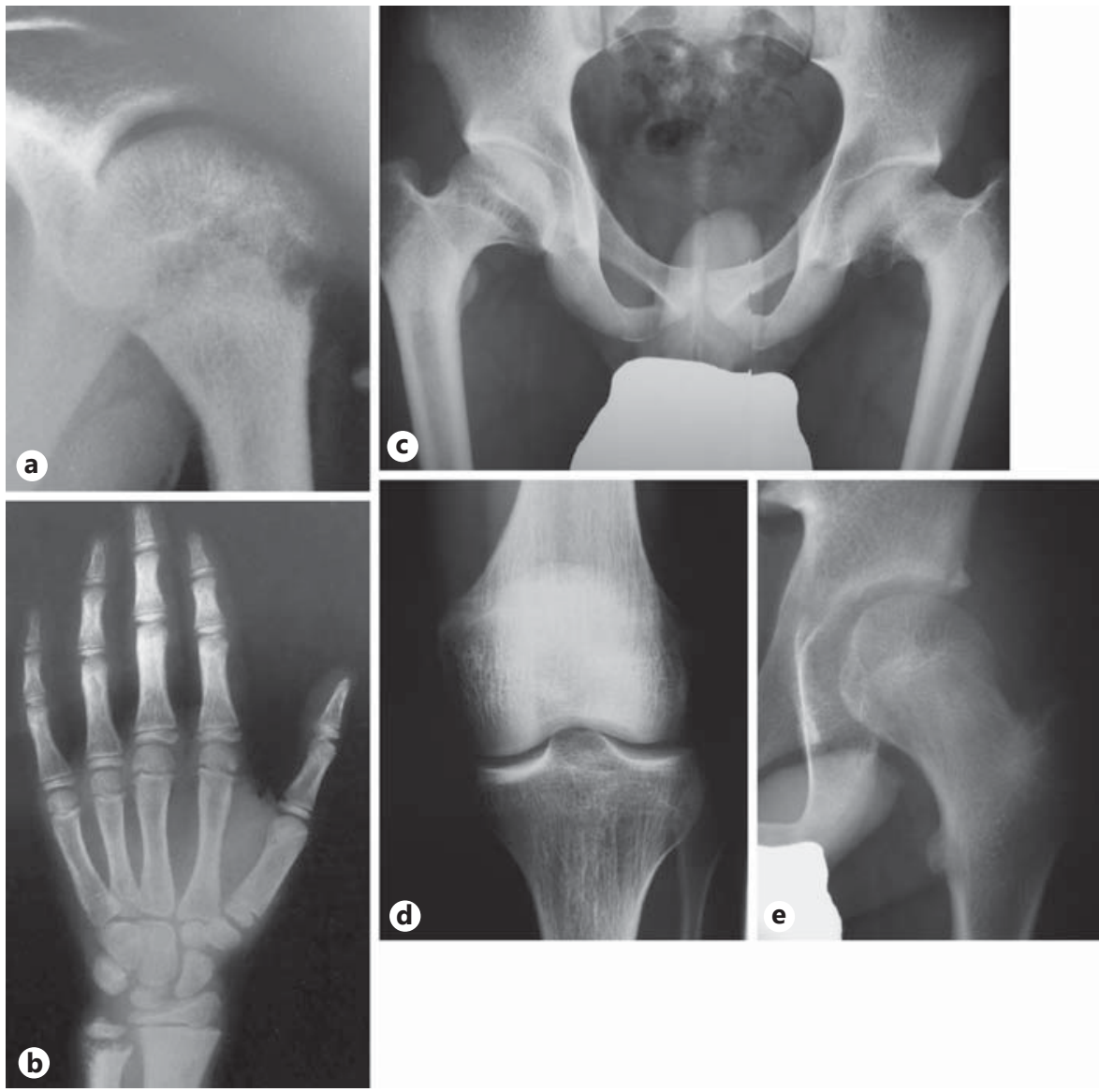

maternal A/B promoter of GNAS, Gsa expression is limited in those tissues resulting in hormonal resistance. In our experience, the mean age at diagnosis is 13 , mostly due to symptoms of hypocalcemia; patients diagnosed after the age of 20 are not rare.

\section{Resistance to Hormones Binding to GPCRs}

$\mathrm{PTH}$ resistance is the main symptom of the disease (for a long time considered as the only one; fig. $2 \mathrm{a}, \mathrm{c})[10,46]$. As in PHP1a, PTH resistance develops over time $[19,47]$. In contrast to PHP1a, in which haploinsufficiency affects all tissues, patients affected with PHP1b maintain a biallelic expression of Gsa in most tissues, in particular in bone. Consequently, their bones respond adequately to elevated PTH levels with an increased bone resorption and demineralization that may resemble rickets or Madelung deformity in children (fig. 4) [48] or severe primary hyperparathyroidism $[49,50]$. TSH resistance is inconstant and usually mild $(4.6 \pm 1.0 \mathrm{mIU} / \mathrm{l})$; in our series, TSH resistance ranged from 2.5 to $10.0 \mathrm{mIU} / 1$ [46]. In the report of Liu et al. [12], TSH ranged between 2.4 and 9.5

$\mathrm{mIU} / \mathrm{l}$, and in the report of Levine and colleagues [51], the TSH level was $4.5 \mathrm{mIU} / \mathrm{l}$ (reference range 0.5-4.5). Free $\mathrm{T} 4$ levels are within the normal range (fig. 2b). As in $\mathrm{PH}$ $\mathrm{P} 1 \mathrm{a}$, we found elevated calcitonin levels in 8 out of $10 \mathrm{pa}-$ tients investigated. Mantovani et al. [52] failed to identify either gonadotropin or growth hormone-releasing hormone resistance in those patients.

\section{AHO and Obesity}

Several features of AHO may be present, rarely all of them in a single patient [41-43]. Some patients present with a typical brachymetacarpy or slender heterotopic ossifications. In our series of patients, the mean body mass index, especially in girls, was significantly higher than that of the general population $(1.0 \pm 0.4 ; \mathrm{p}=0.019)$, and the final height was normal.

\section{Molecular Diagnosis of PHP1b}

Patients affected with PHP1b share a loss of methylation (LOM) at the maternal A/B DMR of GNAS [4]. In addition, some patients present with methylation chang- 
es at the GNAS locus, unequally affecting XL, AS and NESP DMRs [4, 15, 43, 53].

Several subtypes of PHP1b are recognized. About $15-20 \%$ of patients display a LOM restricted to the A/B DMR of GNAS, associated, in all reported cases except one, with a recurrent maternal $3-\mathrm{kb}$ microdeletion within the STX16 gene $[15,43,46]$. In one family, the maternal deletion spanned $4.2 \mathrm{~kb}$ within the STX16 gene, and overlapped the latter by $1.2 \mathrm{~kb}$ [47]. These patients, often clustered in families, are diagnosed with autosomal dominant PHP1b. A very small number of families with autosomal dominant PHP1b show broad loss of imprinting at the GNAS locus and a deletion removing AS exons 3 and $4[16,18]$, or a deletion removing NESP and AS intron 4 [17]. In few sporadic cases, paternal uniparental disomy involving segments or whole chromosome 20 encompassing the GNAS locus is the cause of the absent maternal Gsa expression, hence PHP1b [54-56].

Most patients with PHP1b (80-85\%) are sporadic and show broad loss of imprinting at the GNAS locus, including LOM at the A/B DMR and loss of imprinting affecting at least one additional DMR (gain of methylation at NESP, LOM at AS and/or XL) without microdeletions within the STX16 or AS genes or evidence for paternal uniparental disomy $[43,53]$. They are described as having sporadic PHP1b.

\section{Diagnostic Struggle}

There is no major difference between the phenotypes of patients affected with familial or sporadic forms of PHP1b [46]. Therefore, diagnosis of PHP1b relies on (1) identification of LOM at the A/B DMR of GNAS, (2) characterization of the methylation pattern of the entire GNAS locus, and (3) the search for deletions within STX16 or GNAS and paternal uniparental disomy.

\section{Disease Inheritance}

The reader has already appraised the complexity, diversity and uncertainty of molecular processes affecting the GNAS-imprinted locus, hence triggering disease variants. Parental allelism, genomic localization, genomic or epigenomic lesions arbitrate disease transmission and the phenotype for upcoming babies. Schematically, $\mathrm{PH}$ P1a and PHP1b occur through maternal transmission, whereas $\mathrm{PPHP}$ and $\mathrm{POH}$ are paternally transmitted. Uniparental disomy should be erased through germinal transmission.

\section{Management of Patients with PHP1a and PHP1b}

\section{Hormones}

The objective of PTH resistance treatment is defined as follows: (1) maintain calcemia within the low-normal range (2.0-2.5 mM), (2) prevent hypercalciuria (in children, urinary calcium excretion $<6 \mathrm{mg} / \mathrm{kg} /$ day or a ratio of urinary calcium/urinary creatinin $<0.3 \mathrm{~mm} / \mathrm{mm}$ ), and (3) prevent bone resorption due to elevated PTH. For children, the key treatment is 1a-hydroxylated vitamin D (calcitriol or alfacalcidol), adjusted on growth velocity rather than weight (highest doses during periods of highvelocity growth like infancy or puberty). Unlike patients with hypoparathyroidism, treatment with alfacalcidol or calcitriol rarely leads to hypercalciuria. There is no specific recommendation for 25-OH-vitamin D therapy; however, both the residual activity of the Gsa protein for some patients and the observation that $25-\mathrm{OH}$-vitamin $\mathrm{D}$ facilitates calcium absorption in hypocalcemic patients [57] suggest that the 25-OH-vitamin D level within normal range may help disease management. Calcium supplements (250-1,000 mg according to age) are recommended during the year following the diagnosis of PTH resistance. Adults usually manage to maintain their calcemia and PTH with 25-OH-vitamin D and calcium supplements. Blood calcium, creatinine and $\mathrm{PTH}$, urinary calcium (urine spot in young children, 24-hour urines after age 5), and renal ultrasound should be monitored at regular intervals to adjust treatment.

TSH resistance is usually treated in patients with $\mathrm{PH}-$ P1a by oral thyroxin according to weight to reach normal free T4 level. Except during pregnancy, patients with PHP1b do not require treatment for their TSH resistance.

Off-label growth hormone has been used in patients with PHP1a and short stature with variable results. Unfortunately, clinical trials are lacking to prove the efficacy of the drug [58].

\section{Bone and Obesity}

The treatment of heterotopic ossifications is one of the most important challenges of this disease. Small and nonproblematic ossifications should remain untouched, as they often recur after surgery. Use of non-steroidal antiinflammatory drugs, thiosulfate or bisphosphonates has been reported; by analogy with ossifications following hip replacement, non-steroidal anti-inflammatory drugs should be considered in case of painful recurrence or surgery [59].

Dietary and lifestyle measures to prevent obesity and supportive care for cognitive functions are recommended 
as soon as the diagnosis of PHP1a is established. Cannabinoid receptor type 1 antagonists have been used occasionally for obesity treatment, but are now off the market [60].

\section{Prenatal Diagnosis, Pregnancies and Births}

For patients affected with Gsa haploinsufficiency, preimplantation diagnosis is feasible [61], albeit indebted to the severity of the gonadotropin resistance and to countries' ethical laws. At birth, mutations or epigenetic anomalies may be screened on cord blood [47].
During pregnancies, physicians should pay special attention to maintain TSH levels $<2.5 \mathrm{IU} / \mathrm{l}$, according to international guidelines [62], and correct hypocalcemia by all means. In case of uncontrolled maternal hypocalcemia, or vitamin $\mathrm{D}$ deficiency, newborns are at high risk of neonatal hyperparathyroidism and hypercalcemia. TSH resistance may be present at birth. Therefore, treatment with thyroxin should be started in newborns with elevated TSH (approximately $10 \mu \mathrm{g} / \mathrm{kg} /$ day) even before the result of the molecular biology analysis [63].

\section{References}

1 Albright F, Burnett CH, Smith PH, Parson W: Pseudohypoparathyroidism - an example of 'seabright-bantam syndrome'. Endocrinology 1942;30:922-932.

${ }_{2}$ Werder EA, Fischer JA, Illig R, Kind HP, Bernasconi S, Fanconi A, Prader A: Pseudohypoparathyroidism and idiopathic hypoparathyroidism: relationship between serum calcium and parathyroid hormone levels and urinary cyclic adenosine-3,5'-monophosphate response to parathyroid extract. J Clin Endocrinol Metab 1978;46:872-879.

3 Weinstein LS, Gejman PV, Friedman E, Kadowaki T, Collins RM, Gershon ES, Spiegel AM: Mutations of the Gsa-subunit gene in Albright hereditary osteodystrophy detected by denaturing gradient gel electrophoresis. Proc Natl Acad Sci USA 1990;87:8287-8290.

4 Liu J, Litman D, Rosenberg M, Yu S, Biesecker L, Weinstein L: A GNAS1 imprinting defect in pseudohypoparathyroidism type Ib. J Clin Invest 2000;106:1167-1174.

5 Levine MA: Pseudohypoparathyroidism; in Bilezikian JP, Raisz LG, Rodan GA (eds): Principles of Bone Biology. New York, Academic Press, 2002, vol 2, pp 1137-1163.

6 Linglart A, Menguy C, Couvineau A, Auzan C, Gunes Y, Cancel M, Motte E, Pinto G, Chanson P, Bougneres P, Clauser E, Silve C: Recurrent PRKAR1A mutation in acrodysostosis with hormone resistance. N Engl J Med 2011;364:2218-2226.

7 Michot C, Le Goff C, Goldenberg A, Abhyankar A, Klein C, Kinning E, Guerrot AM, Flahaut P, Duncombe A, Baujat G, Lyonnet S, Thalassinos C, Nitschke P, Casanova JL, Le Merrer M, Munnich A, Cormier-Daire V: Exome sequencing identifies PDE4D mutations as another cause of acrodysostosis. Am J Hum Genet 2012;90:740-745.

8 Lee H, Graham JM Jr, Rimoin DL, Lachman RS, Krejci P, Tompson SW, Nelson SF, Krakow D, Cohn DH: Exome sequencing identifies PDE4D mutations in acrodysostosis. Am J Hum Genet 2012;90:746-751.

-9 Ideraabdullah F, Vigneau S, Bartolomei MS: Genomic imprinting mechanisms in mammals. Mutat Res 2008;647:77-85.
10 Bastepe M: The GNAS locus and pseudohypoparathyroidism. Adv Exp Med Biol 2008; 626:27-40.

11 Hayward BE, Moran V, Strain L, Bonthron DT: Bidirectional imprinting of a single gene: GNAS1 encodes maternally, paternally, and biallelically derived proteins. Proc Natl Acad Sci USA 1998;95:15475-15480.

12 Liu J, Erlichman B, Weinstein LS: The stimulatory $\mathrm{G}$ protein $\alpha$-subunit $\mathrm{Gs} \alpha$ is imprinted in human thyroid glands: implications for thyroid function in pseudohypoparathyroidism types $1 \mathrm{~A}$ and 1B. J Clin Endocrinol Metab 2003;88:4336-4341.

13 Mantovani G, Ballare E, Giammona E, BeckPeccoz P, Spada A: The Gsa gene: predominant maternal origin of transcription in human thyroid gland and gonads. J Clin Endocrinol Metab 2002;87:4736-4740.

14 Hayward B, Barlier A, Korbonits M, Grossman A, Jacquet P, Enjalbert A, Bonthron D: Imprinting of the $G(s) \alpha$ gene GNAS1 in the pathogenesis of acromegaly. J Clin Invest 2001;107:R31-R36.

15 Bastepe M, Fröhlich LF, Hendy GN, Indridason OS, Josse RG, Koshiyama H, Korkko J, Nakamoto JM, Rosenbloom AL, Slyper AH, Sugimoto T, Tsatsoulis A, Crawford JD, Jüppner H: Autosomal dominant pseudohypoparathyroidism type $\mathrm{Ib}$ is associated with a heterozygous microdeletion that likely disrupts a putative imprinting control element of GNAS. J Clin Invest 2003;112:1255-1263.

16 Bastepe M, Fröhlich LF, Linglart A, Abu-Zahra HS, Tojo K, Ward LM, Jüppner H: Deletion of the NESP55 differentially methylated region causes loss of maternal GNAS imprints and pseudohypoparathyroidism type Ib. Nat Genet 2005;37:25-27.

$\checkmark 17$ Richard N, Abeguile G, Coudray N, Mittre H, Gruchy N, Andrieux J, Cathebras P, Kottler ML: A new deletion ablating NESP55 causes loss of maternal imprint of A/B GNAS and autosomal dominant pseudohypoparathyroidism type Ib. J Clin Endocrinol Metab 2012;97:E863-E867.
18 Chillambhi S, Turan S, Hwang D, Chen H, Juppner H, Bastepe M: Deletion of the GNAS antisense transcript result in parent-of-origin specific GNAS imprinting defects and phenotypes including PTH resistance. American Association for Bone and Mineral Metabolism, Montreal, 2008.

19 Maupetit-Méhouas S, Carel JC, Kottler ML, Linglart A: Progressive PTH resistance in pseudohypoparathyroidism (PHP) type 1a and 1b. European Society of Pediatric Endocrinology meeting, Istanbul, 2008.

20 Balavoine AS, Ladsous M, Velayoudom FL, Vlaeminck V, Cardot-Bauters C, d'Herbomez M, Wemeau JL: Hypothyroidism in patients with pseudohypoparathyroidism type Ia: clinical evidence of resistance to TSH and TRH. Eur J Endocrinol 2008; 159: 431-437.

21 Vlaeminck-Guillem V, d'Herbomez M, Pigny P, Fayard A, Bauters C, Decoulx M, Wemeau JL: Pseudohypoparathyroidism Ia and hypercalcitoninemia. J Clin Endocrinol Metab 2001;86:3091-3096.

22 Feng S, Ferlin A, Truong A, Bathgate R, Wade JD, Corbett S, Han S, Tannour-Louet M, Lamb DJ, Foresta C, Agoulnik AI: INSL3/ RXFP2 signaling in testicular descent. Ann NY Acad Sci 2009;1160:197-204.

23 Herman-Giddens ME, Slora EJ, Wasserman RC, Bourdony CJ, Bhapkar MV, Koch GG, Hasemeier CM: Secondary sexual characteristics and menses in young girls seen in office practice: a study from the pediatric research in office settings network. Pediatrics 1997;99: 505-512.

24 Namnoum AB, Merriam GR, Moses AM, Levine MA: Reproductive dysfunction in women with Albright's hereditary osteodystrophy. J Clin Endocrinol Metab 1998;83: 824-829.

25 Linglart A, Carel JC, Garabedian M, Le T, Mallet E, Kottler ML: GNAS1 lesions in pseudohypoparathyroidism Ia and Ic: genotype phenotype relationship and evidence of the maternal transmission of the hormonal resistance. J Clin Endocrinol Metab 2002;87: 189-197. 
26 Klopocki E, Hennig BP, Dathe K, Koll R, de Ravel T, Baten E, Blom E, Gillerot Y, Weigel JF, Kruger G, Hiort O, Seemann P, Mundlos S: Deletion and point mutations of PTHLH cause brachydactyly type E. Am J Hum Genet 2010;86:434-439.

-27 Long DN, Levine MA, Germain-Lee EL: Bone mineral density in pseudohypoparathyroidism type 1a. J Clin Endocrinol Metab 2010;95: 4465-4475.

28 Linglart A: Consequences of PTH resistance on adult bone. Arch Pediatr 2007;14:546-548.

29 Long DN, McGuire S, Levine MA, Weinstein LS, Germain-Lee EL: Body mass index differences in pseudohypoparathyroidism type 1a versus pseudopseudo hypoparathyroidism may implicate paternal imprinting of Galpha(s) in the development of human obesity. J Clin Endocrinol Metab 2007;92:10731079.

-30 Mantovani G, Maghnie M, Weber G, De Menis E, Brunelli V, Cappa M, Loli P, BeckPeccoz P, Spada A: Growth hormone-releasing hormone resistance in pseudohypoparathyroidism type Ia: new evidence for imprinting of the Gs alpha gene. J Clin Endocrinol Metab 2003;88:4070-4074.

- 31 Kaplan FS, Shore EM: Progressive osseous heteroplasia. J Bone Miner Res 2000;15:20842094.

-32 Mouallem M, Shaharabany M, Weintrob N, Shalitin S, Nagelberg N, Shapira H, Zadik Z, Farfel Z: Cognitive impairment is prevalent in pseudohypoparathyroidism type Ia, but not in pseudopseudohypoparathyroidism: possible cerebral imprinting of Gsalpha. Clin Endocrinol (Oxf) 2008;68:233-239.

33 Carel JC, Le Stunff C, Condamine L, Mallet E, Chaussain JL, Adnot P, Garabedian M, Bougneres P: Resistance to the lipolytic action of epinephrine: a new feature of protein Gs deficiency. J Clin Endocrinol Metab 1999;84: 4127-4131.

-34 Wang HY, Watkins DC, Malbon CC: Antisense oligodeoxynucleotides to Gs protein alpha-subunit sequence accelerate differentiation of fibroblasts to adipocytes. Nature 1992;358:334-337.

35 Weinstein LS, Xie T, Qasem A, Wang J, Chen $\mathrm{M}$ : The role of GNAS and other imprinted genes in the development of obesity. Int J Obes (Lond) 2010;34:6-17.

-36 Plagge A, Gordon E, Dean W, Boiani R, Cinti S, Peters J, Kelsey G: The imprinted signaling protein $\mathrm{XL} \alpha \mathrm{s}$ is required for postnatal adaptation to feeding. Nat Genet 2004;36:818-826.

- 37 Williams SR, Aldred MA, Der Kaloustian VM, Halal F, Gowans G, McLeod DR, Zondag S, Toriello HV, Magenis RE, Elsea SH: Haploinsufficiency of HDAC4 causes brachydactyly mental retardation syndrome, with brachydactyly type $\mathrm{E}$, developmental delays, and behavioral problems. Am J Hum Genet 2010;87: 219-228.
38 Ellsworth R, Howard JE: Studies on the physiology of the parathyroid glands. 6 . Some responses of normal human kidneys and blood to intravenous parathyroid extract. Bull Johns Hopkins Hosp 1934;55:296.

- 39 Thiele S, de Sanctis L, Werner R, Grotzinger J, Aydin C, Juppner H, Bastepe M, Hiort O: Functional characterization of GNAS mutations found in patients with pseudohypoparathyroidism type Ic defines a new subgroup of pseudohypoparathyroidism affecting selectively Gsalpha-receptor interaction. Hum Mutat 2011;32:653-660.

40 Thiele S, Werner R, Ahrens W, Hoppe U, Marschke C, Staedt P, Hiort O: A disruptive mutation in exon 3 of the GNAS gene with Albright hereditary osteodystrophy, normocalcemic pseudohypoparathyroidism, and selective long transcript variant Gsalpha-l deficiency. J Clin Endocrinol Metab 2007;92: 1764-1768.

41 de Nanclares GP, Fernandez-Rebollo E, Santin I, Garcia-Cuartero B, Gaztambide S, Menendez E, Morales MJ, Pombo M, Bilbao JR, Barros F, Zazo N, Ahrens W, Juppner H, Hiort O, Castano L, Bastepe M: Epigenetic defects of GNAS in patients with pseudohypoparathyroidism and mild features of $\mathrm{Al}$ bright's hereditary osteodystrophy. J Clin Endocrinol Metab 2007;92:2370-2373.

42 Mariot V, Maupetit-Mehouas S, Sinding C, Kottler ML, Linglart A: A maternal epimutation of GNAS leads to Albright osteodystrophy and parathyroid hormone resistance. J Clin Endocrinol Metab 2008;93: 661-665.

-43 Mantovani G, de Sanctis L, Barbieri AM, Elli FM, Bollati V, Vaira V, Labarile P, Bondioni S, Peverelli E, Lania AG, Beck-Peccoz P, Spada A: Pseudohypoparathyroidism and GNAS epigenetic defects: clinical evaluation of $\mathrm{Al}-$ bright hereditary osteodystrophy and molecular analysis in 40 patients. J Clin Endocrinol Metab 2010;95:651-658.

44 Lebrun M, Richard N, Abeguile G, David A, Coeslier Dieux A, Journel H, Lacombe D, Pinto G, Odent S, Salles JP, Taieb A, GandonLaloum S, Kottler ML: Progressive osseous heteroplasia: a model for the imprinting effects of GNAS inactivating mutations in humans. J Clin Endocrinol Metab 2010;95: 3028-3038.

45 Shore EM, Ahn J, Jan de Beur S, Li M, Xu M, Gardner RJ, Zasloff MA, Whyte MP, Levine MA, Kaplan FS: Paternally inherited inactivating mutations of the GNAS1 gene in progressive osseous heteroplasia. N Engl J Med 2002;346:99-106.

46 Linglart A, Bastepe M, Juppner H: Similar clinical and laboratory findings in patients with symptomatic autosomal dominant and sporadic pseudohypoparathyroidism type Ib despite different epigenetic changes at the GNAS locus. Clin Endocrinol (Oxf) 2007;67: 822-831.
47 Linglart A, Gensure RC, Olney RC, Juppner $\mathrm{H}$, Bastepe M: A novel STX16 deletion in autosomal dominant pseudohypoparathyroidism type Ib redefines the boundaries of a cisacting imprinting control element of GNAS. Am J Hum Genet 2005;76:804-814.

48 Sanchez J, Perera E, Jan de Beur S, Ding C, Dang A, Berkovitz GD, Levine MA: Madelung-like deformity in pseudohypoparathyroidism type 1b. J Clin Endocrinol Metab 2011;96:E1507-E1511.

49 Mahmud FH, Linglart A, Bastepe M, Jüppner H, Lteif AN: Molecular diagnosis of pseudohypoparathyroidism type Ib in a family with presumed paroxysmal dyskinesia. Pediatrics 2005;115:e242-e244.

50 Burnstein MI, Kottamasu SR, Pettifor JM, Sochett E, Ellis BI, Frame B: Metabolic bone disease in pseudohypoparathyroidism: radiologic features. Radiology 1985;155:351-356.

51 Germain-Lee EL, Ding CL, Deng Z, Crane JL, Saji M, Ringel MD, Levine MA: Paternal imprinting of Galpha(s) in the human thyroid as the basis of TSH resistance in pseudohypoparathyroidism type 1a. Biochem Biophys Res Commun 2002;296:67-72.

52 Mantovani G, Bondioni S, Linglart A, Maghnie $M$, Cisternino M, Corbetta S, Lania AG, Beck-Peccoz P, Spada A: Genetic analysis and evaluation of resistance to thyrotropin and growth hormone-releasing hormone in pseudohypoparathyroidism type Ib. J Clin Endocrinol Metab 2007;92:3738-3742.

53 Maupetit-Mehouas S, Mariot V, Reynes C, Bertrand G, Feillet F, Carel JC, Simon D, Bihan H, Gajdos V, Devouge E, Shenoy S, Agbo-Kpati P, Ronan A, Naud-Saudreau C, Lienhardt A, Silve C, Linglart A: Quantification of the methylation at the GNAS locus identifies subtypes of sporadic pseudohypoparathyroidism type Ib. J Med Genet 2011; 48:55-63.

54 Dixit A, Chandler KE, Lever M, Poole RL, Bullman H, Mughal MZ, Steggall M, Suri M: Pseudohypoparathyroidism type $1 \mathrm{~b}$ due to paternal uniparental disomy of chromosome 20q. J Clin Endocrinol Metab 2013;98:E103-E108.

55 Fernandez-Rebollo E, Lecumberri B, Garin I, Arroyo J, Bernal-Chico A, Goni F, Orduna R, Castano L, de Nanclares GP: New mechanisms involved in paternal $20 \mathrm{q}$ disomy associated with pseudohypoparathyroidism. Eur J Endocrinol 2010;163:953-962.

56 Bastepe M, Lane AH, Jüppner H: Paternal uniparental isodisomy of chromosome $20 \mathrm{q}$ (patUPD20q) - and the resulting changes in GNAS1 methylation - as a plausible cause of pseudohypoparathyroidism. Am J Hum Genet 2001;68:1283-1289.

57 Heaney RP, Barger-Lux MJ, Dowell MS, Chen TC, Holick MF: Calcium absorptive effects of vitamin D and its major metabolites. J Clin Endocrinol Metab 1997;82:4111-4116. 
58 Mantovani G, Ferrante E, Giavoli C, Linglart A, Cappa M, Cisternino M, Maghnie M, Ghizzoni L, de Sanctis L, Lania AG, Beck-Peccoz P, Spada A: Recombinant human $\mathrm{GH}$ replacement therapy in children with pseudohypoparathyroidism type Ia: first study on the effect on growth. J Clin Endocrinol Metab 2010;95:5011-5017.

59 Macfarlane RJ, Ng BH, Gamie Z, El Masry MA, Velonis S, Schizas C, Tsiridis E: Pharmacological treatment of heterotopic ossification following hip and acetabular surgery. Expert Opin Pharmacother 2008;9:767-786.

-60 Al-Salameh A, Despert F, Kottler ML, Linglart A, Carel JC, Lecomte P: Resistance to epinephrine and hypersensitivity (hyperresponsiveness) to CB1 antagonists in a patient with pseudohypoparathyroidism type Ic. Eur J Endocrinol 2010;162:819-824.
61 Lietman SA, Goldfarb J, Desai N, Levine MA: Preimplantation genetic diagnosis for severe Albright hereditary osteodystrophy. J Clin Endocrinol Metab 2008;93:901-904.

62 De Groot L, Abalovich M, Alexander EK, Amino N, Barbour L, Cobin RH, Eastman CJ, Lazarus JH, Luton D, Mandel SJ, Mestman J, Rovet J, Sullivan S: Management of thyroid dysfunction during pregnancy and postpartum: an Endocrine Society clinical practice guideline. J Clin Endocrinol Metab 2012;97: 2543-2565.
63 LaFranchi SH: Approach to the diagnosis and treatment of neonatal hypothyroidism. J Clin Endocrinol Metab 2011;96:2959-2967.

-64 Wu WI, Schwindinger WF, Aparicio LF, Levine MA: Selective resistance to parathyroid hormone caused by a novel uncoupling mutation in the carboxyl terminus of Gas: a cause of pseudohypoparathyroidism type Ib. J Biol Chem 2001;276:165-171.

65 Zazo C, Thiele S, Martin C, Fernandez-Rebollo E, Martinez-Indart L, Werner R, Garin I, Hiort O, Perez de Nanclares G: Gsalpha activity is reduced in erythrocyte membranes of patients with psedohypoparathyroidism due to epigenetic alterations at the GNAS locus. J Bone Miner Res 2011;26:1864-1870. 